\title{
Crossing disciplinary boundaries in forest research: An international challenge
}

\author{
by Gordon M. Hickey ${ }^{1}$ and Craig R. Nitschke ${ }^{2}$
}

\begin{abstract}
It is generally recognized that improving our understanding of forest-related research problems will involve amalgamating knowledge and methods from different disciplines. The presence of complex values within complex systems has persuaded many scientists engaged in forestry-related research to begin exploring cross-disciplinary paradigms in order to transcend the limitations of traditional disciplinary thinking. It has been suggested that authentic interdisciplinary programs in the sciences remain rare and that academic departments, academic supervisors and funding agencies present the main barriers to effective cross-disciplinary research among scientists. Despite these barriers, scientists around the world are increasingly approaching their research problems from a cross-disciplinary perspective to provide meaningful solutions to complex environmental problems.
\end{abstract}

Key words: cross-disciplinary, interdisciplinary, forest research, complexity

\section{RÉSUMÉ}

Il est généralement reconnu que l'amélioration de notre compréhension des problèmes de recherche reliés à la foresterie inclura un regroupement des connaissances et des méthodes en provenance de diverses disciplines. La présence de valeurs complexes au sein de systèmes complexes a persuadé plusieurs chercheurs oeuvrant en recherche reliée à la foresterie à entreprendre l'exploration des paradigmes interdisciplinaires de façon à identifier les limites du raisonnement au sein d'une discipline traditionnelle. Il a été suggéré que les vrais programmes interdisciplinaires en sciences demeurent peu nombreux et que les départements et les superviseurs au sein des universités ainsi que les sources de financement constituent les principales barrières limitant la recherche interdisciplinaire efficace parmi les chercheurs. Malgré ces barrières, les chercheurs de toute la planète étudient de plus en plus leurs problèmes de recherche selon une perspective interdisciplinaire dans le but d'obtenir des solutions significatives aux problèmes environnementaux complexes.

Mots clés : interdisciplinaire, recherche forestière, complexité0

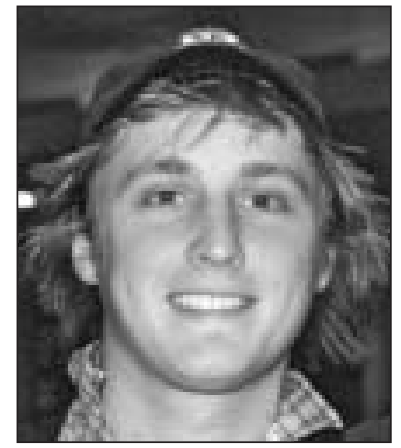

Gordon M. Hickey

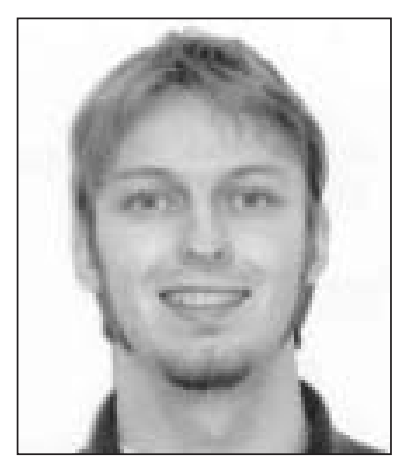

Craig R. Nitschke

\footnotetext{
${ }^{1}$ Sustainable Forest Management Laboratory, 2045 - 2424 Main Mall, University of British Columbia, Vancouver, British Columbia V6T 1Z4. E-mail: ghickey@interchange.ubc.ca

${ }^{2}$ Sustainable Forest Management Laboratory, 2045 - 2424 Main Mall, University of British Columbia, Vancouver, British Columbia V6T 1Z4. E-mail: nitschke@interchange.ubc.ca
}

\section{Introduction}

A human being is part of a whole, called by us the Universe, a part limited in time and space. He experiences himself, his thoughts and feelings, as something separated from the rest - a kind of optical delusion of his consciousness. This delusion is a kind of prison for us, restricting us to our personal desires and to affection for a few persons nearest us. Our task must be to free ourselves from this prison by widening our circles of compassion to embrace all living creatures and the whole of nature in its beauty. ALBERT EINSTEIN

Perceptions change the way that problems are interpreted (Carnap 1966, Klein 1996, Holling et al. 1998, Knight 2002, Aram 2004). In science, there are two recognised perceptions of reality: realism and relativism (anti-realism) ${ }^{3}$ (Wenner

\footnotetext{
3"Realism" endorses an objective reality that exists independent of human perception and social convention (Aram 2004). "Relativism" is the belief that reality is a social construction, a product of mind and language (Knight 2002) and historical and cultural forces (Aram 2004).
} 
1989, Knight 2002, Aram 2004). Through time, academic disciplines ${ }^{4}$ have had a strong influence on the way that humanity perceives reality (Giri 2002, Aram 2004). When described in the context of academia, Aram (2004) noted that "disciplines" imply heightened senses of autonomy, definitiveness, and stability that are traditionally supported by institutional and professional practices. Academic disciplines, therefore, provide cultural frames, social identity and locations for knowledge (Giri 2002). This system has benefits in terms of communication and interaction within each particular discipline (Adamowicz 2004, Bruce et al. 2004). However, it also limits the kinds of questions that can be asked about certain material, methods, concepts, results and the criteria for truth and validity (Klein 1990, Bruce et al. 2004).

Today, the traditionally rigid boundaries between different disciplines have given way to a situation where blurred boundaries are being promoted (Giri 2002). According to Barry and Oelschlaeger (1996) the presence of complex values within complex systems has persuaded many scientists to begin exploring cross-disciplinary paradigms in order to transcend the limitations of traditional disciplinary thinking. For example, Orr (1993), Hammer (1998), Pister (1999) and Wang (2002) have called for increased collaboration to address ecological issues. In forestry, the blurring of disciplinary boundaries is evident in the emergence, and general acceptance, of new disciplines such as conservation biology and landscape ecology. It is now generally recognized that improving our understanding of many forestry-related research problems will involve amalgamating knowledge and methods from different disciplines [see, for example, Steele and Stier (2000), Coté et al. (2001), Wang (2002), Kenny (2003), Adamowicz (2004), Davidson and Frickel (2004)]. This recognition has led to a broad range of forestry-related research programmes that either explicitly or implicitly embrace cross-disciplinary principles. Bruce et al. (2004) defined the most important categories of cross-disciplinary research as follows:

Transdisciplinary research: organizing knowledge around complex heterogeneous domains rather than specific disciplines (see Nowotny et al. 2001).

Multidisciplinary research: using a range of disciplinary perspectives, with each discipline working in a self-contained manner.

Interdisciplinary research: using a range of disciplinary perspectives and integrating them to provide a holistic or systemic outcome.

It is important to note that the value of these cross-disciplinary research approaches varies across different research areas and contexts (Adamowicz 2004, Bruce et al. 2004). Nevertheless, it is generally agreed that graduate-level education needs to prepare students for an increasingly interdisciplinary, collaborative, and global job market (Golde and Gallagher 1999).

\footnotetext{
${ }^{4}$ The term "discipline" has been used to signify a method of ordering knowledge for teaching and learning since the early Middle Ages (Aram 2004). According to Bruce et al. (2004), "disciplines" can be seen as "... stable systemic communities within which researchers concentrate their experience into a particular worldview."
}

\section{Challenges to Interdisciplinary Research}

With reference to the education of graduate students in the sciences, Sung et al. (2003) stated that "[b]right young scientists will gravitate toward the rich scientific opportunities at disciplinary boundaries, but must cross current institutional and cultural barriers that are neither trivial nor intransigent." Researchers tackling the many challenges associated with sustainable forest management (SFM) are often required to achieve a high degree of specialization that is endemic to science and often results in limited networking across disciplines. According to Sung et al. (2003), authentic interdisciplinary programs in the sciences remain rare. In a survey of researchers funded under the National Science Foundation's Environmental Research and Education portfolio (USA), Rhoten and Parker (2004) found that many young scientists felt tension between the scientific promise of an interdisciplinary research path and the academic prospect of the tenure track. Furthermore, Sung et al. (2003) noted that there is often a strong economic incentive for graduate students to complete coursework quickly and to move into a laboratory where they typically work on a specific project.

Many authors agree that effective interdisciplinary research requires new modes of thinking that transcend traditional discipline-based academic structures and systems, particularly in terms of rewards and resource allocation (Golde and Gallagher 1999, Fitzpatrick 2002, Niesenbaum and Lewis 2003, Sung et al. 2003, Adamowicz 2004, Bruce et al. 2004). Sobel (2003) noted that the process of peer review often limits the ability of universities to promote and reward real interdisciplinary efforts. This is especially obvious during tenure reviews and funding applications that are often constrained by disciplinary standards and definitions of what is good (Sobel 2003, Cech and Rubin 2004). In terms of doctoral education, Golde and Gallagher (1999) identified academic departments, academic supervisors and funding agencies as the main barriers to effective cross-disciplinary research among doctoral scientists. Pister (1999) suggested that these barriers exist because of the propensity of scientists to think "in boxes," resulting in the increased specialisation of graduate school. Nevertheless, scientists around the world are increasingly approaching their research problems from a cross-disciplinary perspective. This observation is particularly relevant to forestry-related research, where social, economic and environmental complexities challenge researchers to explore new perspectives from a diverse range of fields. Wang (2002) stated that collaboration at the conceptual, procedur$\mathrm{al}$, and operational levels is required to solve the complex or "wicked" problems faced by scientists in forestry-related research. In this context, Golde and Gallagher (1999) suggested that students with interdisciplinary interests should 1) attempt to gain knowledge in more than one field, or 2) collaborate with a researcher outside of their home discipline.

\section{International Perspectives on Interdisciplinary Forest Research}

The challenges associated with conducting interdisciplinary research transcend many scales and topics. In this issue of The Forestry Chronicle, Innes (Canada) and Vedeld and Krogh (Norway) discuss the issues being faced in an education system that is challenged by the concept of interdisciplinary teaching and research. Innes (this issue) takes this a step fur- 
ther to consider the implications of these challenges for forest practitioners. Porro et al. (Brazil) discuss the Amazon Initiative, a collaboration of institutions and scientists representing six countries within the Amazon Basin. In a similar fashion, MacNab (Canada) discusses the role that the Sustainable Forest Management Network has played in developing a collaborative and interdisciplinary network of scientists and project teams across Canada. Sonwa et al. (Cameroon) state the need for the integration and collaboration of institutions to develop a successful integrated pest management system for cocoa-agroforestry systems in Western and Central Africa. Strimbu et al. (Romania) have combined parametric with non-parametric statistical techniques to evaluate the impacts of rapid economic transition on forest management in Romania. Mathey et al. (Canada), Johnson and Peterson (USA), Littell and Peterson (USA) and Kijazi (Canada) present different perspectives on the need to integrate disciplines to improve forest planning and forecasting. These papers incorporate geography, mathematics, landscape ecology, fire science, atmospheric science, geographic information systems (GIS), and modelling. Innes (this issue) states "the nature of forestry is changing rapidly, with the social component becoming as or even more important than the traditional biophysical components." In this issue, Allen (Canada), Acharya et al. (Nepal), Robiglio and Mala (Cameroon), Lecomte et al. (Canada), and Banjade and Ojha (Nepal) present perspectives on cross-disciplinary research that incorporate social research techniques. These papers use participatory research methods, traditional knowledge of indigenous groups, and/or mapping tools to investigate complex interactions between forest management and local forest communities.

The papers in this issue provide a variety of perspectives on cross-disciplinary research at a range of scales. The integration of disciplines is based on the need to address complex problems and similarities that clearly exist across borders. These similarities can, hopefully, inform forest practitioners as they pursue SFM in different parts of the world.

\section{Conclusion}

Today's scientists are beginning to recognise the importance of asking complex questions to better address complex problems. In these cases, cross-disciplinary research will be necessary to ensure meaningful and robust solutions. The purpose of this special issue of The Forestry Chronicle is to highlight the innovative work of scientists from around the world and present their responses to the challenges of interdisciplinary research in forestry. Our session at the XXII IUFRO World Congress was designed to provide a forum where scientists could share international perspectives on the role of interdisciplinary work in their research, and discuss approaches to some of the practical problems they have faced.

\section{References}

Adamowicz, W.L. 2004. "Big science": Is the move towards interdisciplinary research teams in forest management science a good thing? The Forestry Chronicle 80(5): 542-546.

Aram, J.D. 2004. Concepts of interdisciplinarity: Configurations of knowledge and action. Human Relations 57(4): 379-412.

Barry, D. and M. Oelschlaeger. 1996. A science for survival: values and conservation biology. Conservation Biology 10(3): 905-911.
Bruce, A., C. Lyall, J. Tait and R. Williams. 2004. Interdisciplinary integration in Europe: the case of the Fifth Framework programme. Futures 36(4): 457-470.

Carnap R. 1966. An Introduction to the Philosophy of Science. Dover Publications, Inc., New York. 300 p.

Cech, T.R. and G.M. Rubin. 2004. Nurturing interdisciplinary research. Nature Structural \& Molecular Biology 11(12): 1166-1169. Coté, M.-A., D. Kneeshaw, L. Bouthillier and C. Messier. 2001. Increasing partnerships between scientists and forest managers: Lessons from an ongoing interdisciplinary project in Québec. The Forestry Chronicle 77(1): 85-89.

Davidson, D.J. and S. Frickel. 2004. Understanding environmental governance - A critical review. Organization \& Environment 17(4): 471-492.

Fitzpatrick, J.J. 2002. Multidisciplinary and interdisciplinary research: What it is and what it is not. Applied Nursing Research 15(2): 59.

Giri, A.K. 2002. The calling of a creative transdisciplinarity. Futures 34(1): 103-115.

Golde, C.M. and H.A. Gallagher. 1999. The Challenges of Conducting Interdisciplinary Research in Traditional Doctoral Programs. Ecosystems 2: 218-285.

Hammer, R.D. 1998. Space and time in the soil landscape: the illdefined ecological universe. In: D.L. Peterson and V.T. Parker (eds.). Ecological Scale: Theory and Applications. pp. 105-140. Columbia University Press, New York. 615 p.

Holling, C.S., F. Berkes and C. Folke. 1998. Science, sustainability and resource management. In F. Berkes and C. Folke (eds.). Linking Social and Ecological Systems. pp. 342-362. Cambridge University Press. 459 p.

Kenney, W.A. 2003. A strategy for Canada's urban forests. The Forestry Chronicle 79(4): 785-789.

Klein, J.T. 1990. Interdisciplinarity: History, Theory and Practice. Wayne State University Press, Detroit. 331 p.

Klein, J.T. 1996. Crossing boundaries: Knowledge, disciplinarities, and interdisciplinarities. The University of Virginia Press, Charlottsville.

Knight, P.T. 2002. Small-Scale Research. Sage Publications Ltd., London. 223 p.

Niesenbaum R.A. and T. Lewis. 2003. Ghettoization in Conservation Biology: how interdisciplinary is our teaching? Conservation Biology 17 (1): 6-10.

Nowotny, H., P. Scott and M. Gibbons. 2001. Re-Thinking Science: Knowledge and the Public in an Age of Uncertainty. Polity Press, Cambridge, UK.

Orr, D.W. 1993. The problem of disciplines: the discipline of problems. Conservation Biology, 7: 11-12.

Pister, E.P. 1999. Professional obligations in the conservation of fishes. Environmental Biology of Fishes 55: 13-20.

Rhoten, D. and A. Parker. 2004. Risks and rewards of an interdisciplinary research path. Science 306(5704): 2046-2046.

Sobel, A. 2003. Comments on globalization, interdisciplinary research, myopia and parochialism, government, convergence, and culture. Journal of International Management 9(4): 419-425.

Steele, T.W. and J.C. Stier. 2000. The Impact of Interdisciplinary Research in the Environmental Sciences: A Forestry Case Study. Journal of the American Society for Information Science. 51: 476484.

Sung, N.S., J.I. Gordon, G.D. Rose, E.D. Getzoff, S.J. Kron, D. Mumford, J.N. Onuchic, N.F. Scherer, D.L. Sumners and N.J. Kopell. 2003. Educating Future Scientists. Science 301: 1485.

Wang, S. 2002. Wicked problems and metaforestry: Is the era of management over? The Forestry Chronicle 78(4): 505-510.

Wenner, A.M. 1989. Concept-centered versus organism-centered biology. American Zoology 29: 1177-1197. 